\title{
EDUCAÇÃO A DISTÂNCIA NO BRASIL: POTENCIALIDADES E FRAGILIDADES
}

\author{
Lílian FERRUGINI ${ }^{1}$ \\ Donizeti Leandro de SOUZA ${ }^{2}$ \\ Raphael MORAIS \\ Cintia Loos PINTO
}

\author{
${ }^{1}$ Doutoranda em Administração (UFLA) - lilianufjf@yahoo.com.br \\ ${ }^{2}$ Doutorando em Administração (UFLA) - souza.doni@yahoo.com.br \\ ${ }^{3}$ Graduando em Administração Pública (UFLA) - raphaelmoraisufla@ gmail.com \\ ${ }^{4}$ Professora Assistente A da Universidade Federal de Viçosa - cintialoosp@gmail.com
}

\section{Recebido em: 05/05/2014 - Aprovado em: 30/06/2014 - Disponibilizado em: 30/07/2014}

\begin{abstract}
Resumo:O Governo brasileiro, no que tange ao sistema educacional do país, tem criado programas, como o sistema Universidade Aberta do Brasil (UAB), para ampliar o acesso à educação superior em diversas regiões. Nesse sentido, este ensaio teórico está pautado na necessidade de analisar os aspectos da Educação a Distância (EaD) quanto as suas fragilidades e potencialidades capazes de inibir ou disseminar a oferta de cursos superiores. Como conclusões identificou-se que as principais fragilidades que a gestão da $\mathrm{EaD}$ deve priorizar são: o desconhecimento e a falta de preparo dos alunos para a modalidade de EaD; ineficiência do material didático; indisponibilidade de bibliotecas físicas e virtuais de qualidade. Dentre as potencialidades foram identificados a abrangência e quebra de barreiras geográficas e a inserção no meio educacional de um público com limitações de acesso para os ditames da política pública educacional.
\end{abstract}

Palavras-chave: Educação a Distância. Política Pública. Sistema UAB. Potencialidades. Fragilidades.

Abstract:The Brazilian Government, in regard to the educational system has created programs such as the Open University system of Brazil (OUB), to expand access to higher education in different regions. In this sense, this theoretical essay is guided by the need to examine aspects of distance education (DE) and its weaknesses and potential that can increase and disseminate the offering of higher education. As the conclusions it was identified that Government should prioritize the unfamiliarity and lack of preparation of students for distance learning modality; inefficient instructional materials; unavailability of physical and virtual quality libraries, among other issues. About the potentialities it was identified the breakdown of geographical barriers, the inclusion of people in the educational environment with limitations to the dictates of public education policy.

Keywords: Online Education. Public Politics. System OUB. Potentialities. Fragilities

\section{Introdução}

Melhorias no nível educacional de uma sociedade sempre estiveram na pauta de discussões do setor público e do privado. A partir da década de 1990, o tema foi aquecido no âmbito público brasileiro e passou a fazer parte das estratégias da gestão pública para o desenvolvimento do país, principalmente no que tange à educação superior (SARAIVA;

NUNES, 2010).

\begin{abstract}
Esse estudo está pautado na necessidade de identificação e análise das ferramentas de políticas públicas utilizadas para aumentar a oferta dos cursos superiores, em especial na modalidade à distância, que a partir do sistema Universidade Aberta do Brasil (UAB), tem ampliado o acesso à educação superior no país. O objetivo do estudo, então, é identificar quais as fragilidades atuais que entravam a efetivação
\end{abstract}


da política pública de educação superior à distância no Brasil e quais são as potencialidades que a dinamizam.

O estudo se mostra relevante, pois há a necessidade de se identificar e analisar algumas variáveis importantes para as estratégias das políticas públicas educacionais que estão operando no sentido de reagir à oferta dos cursos à distância e buscando atender a crescente demanda por cursos superiores nas mais diversas regiões do Brasil.

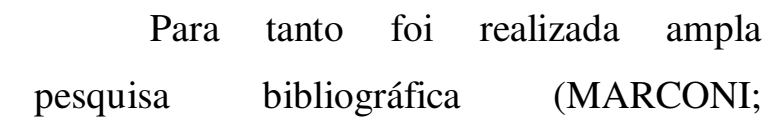
LAKATOS, 2001), a qual buscou expandir a percepção sobre o conteúdo em pauta.

\section{Contextualização da política pública brasileira para a educação superior}

O conceito de política pública compreende ações, atividades e mecanismos que utilizam recursos financeiros públicos para atender as demandas e as necessidades da sociedade, seja relacionada à saúde, emprego, trabalho, segurança, educação, dentre outros (MATIAS-PEREIRA, 2008).

Objetivando demonstrar a importância e a preocupação que o processo educacional sempre gerou em autoridades na capacitação e desenvolvimento de habilidades dos indivíduos, Costa, Barbosa e Goto (2011) relatam que a educação tem sido fator de preocupações desde a época da colonização do Brasil em que foi instalada a primeira escola na cidade de Salvador. Posteriormente, com a chegada da família real no Brasil, várias escolas foram implantadas com o intuito de elevar o nível cultural do país e criar pessoas capacitadas para apoiar o governo que ora se instalaria no novo território.

A partir da década de 1950, período em que o processo de industrialização foi dinamizado no Brasil, a precariedade de mão de obra qualificada fez com que autoridades (Governo) voltassem suas atenções para expansão da educação. A partir de então foi instituída em 1961 a Lei de Diretrizes e Bases da Educação a qual não repercutiu efeito positivo inicialmente esperado. Contudo, em 1969 novos decretos foram instituídos buscando complementação e aparato para o que já havia sido estabelecido em termos de políticas voltadas à educação, mas devido ao período de ditadura militar, não houve expansão e significativas mudanças para a educação superior no país (MEC, 2007; Costa; Barbosa; Goto, 2011).

Já em 2001 a Lei no 10.172 instituiu o Plano Nacional da Educação (PNE) estipulando a educação como direito de todos os cidadãos; como fator de desenvolvimento social e econômico para o país e como instrumento de combate a pobreza e inclusão social. Para a educação superior, em específico, foram instituídas algumas prerrogativas, como por exemplo: investir na oferta de cursos noturnos, modulares e 
sequenciais; ofertar até o final da década passada, educação superior para cerca de $30 \%$ dos jovens de 18 a 24 anos; estabelecer amplo sistema de EaD, entre outros (MEC, 2007; COSTA; BARBOSA; GOTO, 2011).

Entretanto, para concretização de tais ações, Pinto (2002) afirma que o governo deveria ter investido em torno de $10 \%$ de seu PIB para atingir as metas propostas pelo PNE e não apenas os $4 \%$ que foram de fato investidos.

Posteriormente, assim como advogam Costa, Barbosa e Goto (2011), instituiu-se o PDE (Plano de Desenvolvimento da Educação) como um passo a mais para desenvolver ferramentas eficientes à ampliação da oferta da educação. Nesse ensaio foca-se apenas nas políticas públicas voltadas para a educação superior, as quais são fundamentais e responsáveis pelo "desenvolvimento econômico e social, fazendo da educação superior, enquanto formadora de recursos humanos altamente qualificados, seja como peça imprescindível na produção científico-tecnológica, elementochave da integração e da formação da Nação" (MEC, 2007, p. 25).

Ainda sobre o PDE, uma de suas atividades foi a criação do Programa de Apoio a Planos de Reestruturação e Expansão das Universidades Federais (REUNI) em parceria com a Associação Nacional dos Dirigentes das Instituições Federais de Ensino Superior (ANDIFES), com o objetivo primordial de expandir o número de vagas nas Instituições Federais mediante investimento na educação, dando maior autonomia para as Universidades. Foi criado também, em conjunto com o REUNI, o Plano Nacional de Assistência Estudantil (PNAES) para dar apoio e suporte financeiro aos estudantes mais carentes (MEC, 2007).

Também como forma de atender a demanda por educação superior e ao mesmo tempo democratizar seu acesso, a partir da educação superior privada, foram instituídas algumas retificações nos processos de financiamento dos programas: PROUNI (Programa Universidade para Todos) e FIES (Fundo de Financiamento ao Estudante do Ensino Superior). Esses programas buscam ofertar cursos por meio da iniciativa privada a partir de suporte governamental. Nesse sentido, não se pretende alcançar todas as dimensões a respeito dos respectivos programas, mas enfatizar que eles contribuíram significativamente para a oferta e democratização da educação superior, algo primordial nas estratégias da Política Pública de Educação do Brasil (MEC, 2007; COSTA; BARBOSA; GOTO, 2011).

Dando continuidade aos programas de expansão da educação superior pública, em 2005 através de uma parceria do Ministério da Educação (MEC) com a ANDIFES e Empresas Estatais, foi regulamentado o Sistema Universidade Aberta do Brasil (UAB) o qual proporcionou crescimento 
considerável da oferta de educação superior a distância no país. A UAB é uma política pública articulada entre a Secretaria de Educação a Distância (SEED/MEC) e a Diretoria de Educação a Distância (DED/CAPES), buscando desenvolver a modalidade de EaD para expandir e interiorizar a educação superior no país frente às exigências da globalização e do mercado de trabalho contemporâneo (COSTA; BARBOSA; GOTO, 2011; UAB/CAPES, 2013).

O sistema UAB é um esforço das estratégias das políticas públicas para a educação superior no sentido de promover educação gratuita de qualidade para camadas dispersas e distintas da sociedade (MATIASPEREIRA, 2008).

Ademais, torna-se importante destacar que é por meio do uso da metodologia de educação a distância que o Sistema UAB busca atender demandas locais na preparação e capacitação de indivíduos situados em regiões mais carentes da sociedade para que os indivíduos possam atuar no mercado de trabalho de forma mais igualitária, justa e competitiva (MORÉ, et al., 2011; ALVES, 2009).

Assim, o sistema UAB tem sido alvo de muitas pesquisas para identificação de sua real contribuição enquanto dinamizador e propulsor da oferta de cursos de nível superior à distância. Nesse sentido, busca-se também identificar as fragilidades e potencialidades que esse sistema perpassa na atualidade, o que será analisado na próxima seção.

\section{Síntese das Fragilidades e} Potencialidades da EaD

Uma das críticas das autoras Gatti e Barreto (2009) diz respeito à precária qualidade na formação que os cursos superiores a distância têm oferecido, principalmente para professores que ministrarão aulas para o ensino básico e médio. Elas enfatizam que o número de pessoas graduadas por cursos superiores à distância têm sido relevante para os índices estatísticos do país e tem sido importante com vistas ao desenvolvimento. Contudo, apesar de contribuir para sanar/reduzir a crise de oferta de ensino superior, pode-se criar entraves e fragilidades relativos ao conhecimento adquirido pelos alunos (futuros profissionais), ou seja, formar profissionais com capacitação limitada para exercício de suas funções. Assim, identifica-se uma fragilidade/lacuna existente entre ensino, formação e aprendizagem, o que pode ser explicado, em parte, pela grande falha do processo didático-pedagógico, falta de corpo docente preparado e especializado para ministrar os conteúdos dos cursos aplicados na modalidade a distância, falta de controle e avaliação constante da qualidade dos cursos, ineficiente material didático, dentre outros.

Belloni (2008) enfatiza que os alunos da modalidade à distância estão cada vez mais 
passivos em relação à criação e desenvolvimento de novos conhecimentos e habilidades. Ademais, os alunos da $\mathrm{EaD}$ estão absorvendo muito mais informações do que propriamente elaborando conteúdos e dinamizando novos conhecimentos a partir das informações disponibilizadas. Relata-se então que os alunos não possuem visão crítica do mundo e não saberão como agir mediante situações variadas que a profissão venha a exigir.

Outra fragilidade apontada em relação a Educação a Distância que impede a maior qualidade dos cursos e a construção de novos conhecimentos é a falta de acervo impresso (biblioteca) de qualidade disponível para os alunos nos polos de apoio presencial. Garcez e Rados (2002) enfatizam em seu estudo que a biblioteca física ainda é meio de informação e busca de conhecimento mais utilizado pelos alunos. A não disponibilização de bibliotecas dificulta a aprendizagem na medida em que os alunos ficam restritos às apostilas e alguns materiais disponibilizados pelos professores/ tutores na plataforma virtual de ensinoaprendizagem. Assim, Garcez e Rados (2002, p. 23) afirmam que "os bens e serviços bibliotecários devem constar no planejamento dos cursos a distância e estarem disponíveis de maneira compatível com as necessidades dos seus usuários".

Para sanar o problema de acervo impresso, bibliotecas virtuais ou eletrônicas eficientes e com grande quantidade de títulos/acervo seria uma opção mais acessível para atender à demanda dos estudantes que se encontram longe de seu respectivo polo (Blattmann, 2001), algo ainda incipiente na maioria das Universidades que ministram cursos à distância.

Outro entrave a ser destacado, talvez o mais importante, é a falta de habilidade e conhecimento profundo do método de educação a distância dos mediadores (professores/tutores). A formação, o desenvolvimento de habilidades e a capacidade didática online dos docentes são cruciais para aprendizagem e qualidade do conhecimento repassado aos discentes. Diante de tal fato, destaca-se que os mediadores que atuarão nos cursos à distância devem passar por treinamentos efetivos que irão proporcionar desenvolvimento das habilidades tecnológicas e conceituais necessárias ao desenvolvimento eficiente do curso (LIU, 2012; MALHEIROS; FERRAZ; MUENCHEN, 2011). Contudo, os cursos de capacitação proporcionados aos mediadores ainda estão muito aquém da real necessidade didática dessa modalidade de ensino.

Redpath (2012) enfatiza a importância que o instrutor/mediador possui no processo de aprendizagem, relatando que o mesmo possui significativa influência na satisfação dos alunos com o curso. Arbaugh e Benbunam-Fich (2006) relatam que o ensino exige que os professores estejam realmente presentes em seus cursos e profundamente 
engajados em comunidades de aprendizagem indepedente da modalidade de educação. Em outras palavras, a $\mathrm{EaD}$ exige que o profissional docente consiga transpor seu conhecimento prático para o ensino virtual, no sentido de demonstrar clareza de suas competências, habilidades de criar modelos e novas inserções didáticas para mediar o processo educacional online Machado (2012), algo ainda distante e incipiente no Sistema UAB.

Vale destacar que muitos alunos aderem a essa modalidade de ensino por presumirem ser um modelo mais fácil de aprendizagem e realização das atividades do curso, por demandar menos horas de estudos e, consequentemente obter um diploma de graduação sem muitos esforços. Todavia, essa modalidade exige dedicação, disciplina e criação do próprio conhecimento. A falta de conhecimento sobre o verdadeiro modelo de funcionamento dessa modalidade faz com que a evasão seja um agravante para crescimento e confiabilidade da EaD. Esse fato pode ser modificado caso haja uma conscientização e preparação do corpo discente antes mesmo de efetivarem e iniciarem as respectivas disciplinas de cada curso. Corroborando, Andrade (2010) em seu estudo enfatiza que se fossem dadas algumas orientações aos alunos sobre como organizar melhor seu tempo, como proceder para estudar e utilizar de modo eficiente as TIC`s (Coelho et al. (2011), haveria redução do índice de evasão dos cursos a distância.

Machado (2012) advoga que a EaD ainda carece de meios que possam controlar, medir e avaliar indicadores relativos à qualidade dos cursos e do conhecimento adquirido pelos discentes. Destaca-se também a importância de se manter os alunos motivados por meio de constantes processos de avaliação e feedback de seu desempenho (MO; ZHAO, 2012).

Em contrapartida, as potencialidades da Educação a Distância são destacadas por vários autores, como por exemplo, MatiasPereira (2008); Moré et al. (2011); dentre outros. Eles buscam demonstrar os benefícios da EaD enquanto uma importante ferramenta de expansão, interiorização e dinamização da educação superior. Essa modalidade não somente amplia oportunidades para indivíduos e grupos sociais dispersos no espaço geográfico, mas também cria meios para os indivíduos adequarem seus estudos aos seus ritmos de vida e de trabalho.

A EaD tem alcançado seu principal objetivo, ou seja, elevar o número de indivíduos com curso superior. Assim, identifica-se seu potencial de disponibilizar educação "em massa" para as mais diversas regiões do país que em sua maioria não estão alicerçadas pela presença física das IPES. Dados coletados pelo (MEC/INEP, 2013) mostram que do ano de 2011 para 2012 o crescimento do número de matrículas em cursos ofertados presencialmente na esfera 
pública foi de $3,1 \%$, enquanto que o de Educação a Distância foi de $12,2 \%$ no mesmo período, sendo que essa modalidade representa mais de $15 \%$ do total de matrículas no ensino superior. A EaD pública ainda pode avançar consideravelmente em sua oferta de cursos (MEC/INEP, 2012), apesar de já ter alcançado patamares elevados em um período curto de tempo, se comparados à educação tradicional. A Figura 1 esboça resumidamente algumas potencialidades e fragilidades da $\mathrm{EaD}$

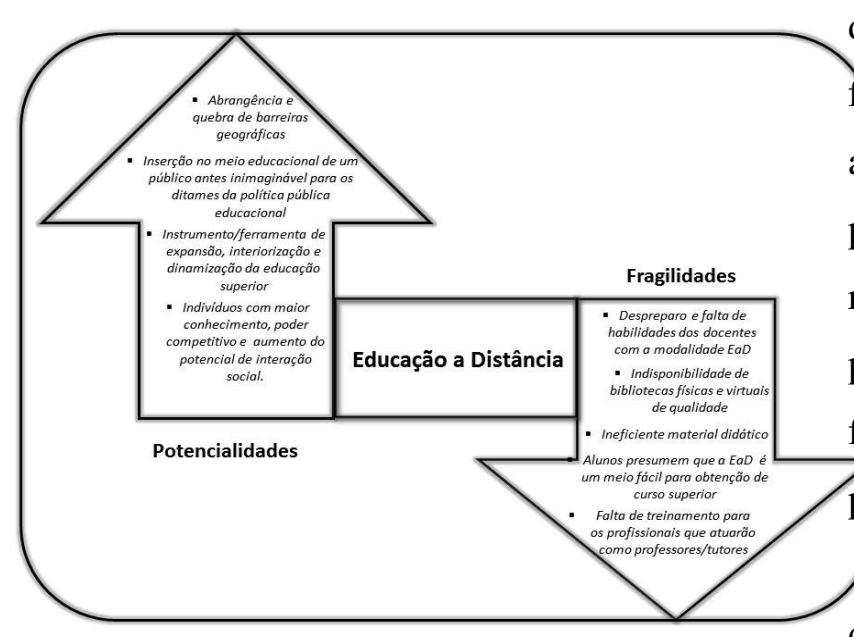

Figura 1 - Potencialidades e Fragilidades da Educação a Distância

Fonte: Elaborado pelos autores.

\section{Reflexões Finais}

A EaD ainda é vista por muitos alunos como um meio fácil e rápido de obter um diploma de curso superior, não depositando confiança e maiores esforços para adquirir novos conhecimentos e visão crítica do mundo a partir das informações disponibilizadas no curso. A mudança desse cenário seria possível a partir da conscientização dos futuros alunos sobre o método de ensino-aprendizagem, totalmente diferente do modelo presencial (ANDRADE, 2010; COELHO, et al., 2011).

O corpo de dirigentes e professores/tutores nem sempre parecem possuir formação e capacitação adequadas para o exercício de suas funções. Essa falha ocorre, pois na maioria das vezes, não são ministrados cursos de capacitação adequados para exercício da função de tutores da $\mathrm{EaD}$.

Em relação ao corpo docente (atuantes da modalidade presencial) são, ffequentemente, convidados para ministrarem a disciplinas, sem receberem nenhuma p eparação para tal. Assim, identifica-se uma relação de oportunismo na contratação de p ofessores na medida em que envolve laços familiares e de amizades ao invés de p ocessos rígidos de seleção.

Observa-se também que muitos dirigentes/professores/tutores têm na Educação a Distância um meio de aumentar ou complementar a sua a renda e, talvez por isso, não empenhem maiores esforços para ministrarem boas aulas e melhorar a qualidade dos cursos, visto não terem relacionamento profundo e contínuo com o trabalho que desempenham. Cabe destacar que não são todos os atores (gestores/professores/tutores) que tratam a $\mathrm{EaD}$ da forma como abordada.

Muitos acreditam no potencial dessa modalidade de educação e desempenham suas 
funções da melhor maneira possível, buscando interação direta e constante com o processo de ensino-aprendizagem, a qual requer aperfeiçoamento constante $\mathrm{e}$ envolvimento mais coletivo, duradouro e recíproco por parte dos docentes Gatti e Barreto (2009), a fim de sistematizar e disseminar o processo de ensinoaprendizagem e equacionar de modo amplo as dificuldades que surgem ao longo dos cursos.

Em relação às potencialidades da $\mathrm{EaD}$, há de se ressaltar seu poder de alcance, abrangência e inserção de um público antes inimaginável para os ditames da política pública educacional. Nesse sentido, julga-se que o primeiro passo já foi dado para dinamizar essa modalidade de educação e, apesar de ainda carecer em alguns pontos, citados ao longo desse ensaio, identifica-se que a qualidade da $\mathrm{EaD}$ depende de uma série de processos e fatores que envolvem desde o planejamento da implantação do curso, passando por adequada seleção, qualificação e desenvolvimento de habilidades específicas dos profissionais envolvidos, além de controle e avaliação constante dos cursos. Esse contexto torna-se possível a partir da plena participação dos gestores e formuladores de políticas públicas educacionais e pode ser exponencialmente dinamizada se esses preceitos forem, de fato, efetivados. Desta forma, a $\mathrm{EaD}$ pode se tornar uma ferramenta realmente eficiente para alavancar o potencial educacional do país, com fortes tendências ao desenvolvimento da sociedade e da economia.

\section{REFERÊNCIAS BIBLIOGRÁFICAS}

ALVES, J. R. M. A história da EAD no Brasil. In: LITTO, F. M.; FORMIGA, M. (Org.). Educação a Distância - o estado da arte. 1. ed. São Paulo: Pearson Education do Brasil, v. 01, p. 09-13, 2009.

ANDRADE, A. F. A. Análise da evasão no curso de administração a distância: projetopiloto UAB: um enfoque sobre a gestão. 138p. 2010. Dissertação (Mestrado em Administração). FAECE, Universidade de Brasília, Brasília, 2010.

ARBAUGH, J. B; BENBUNAN-FICH, R. An Investigation of Epistemological and Social Dimensions of Teaching in Online Learning Environments. Academy of Management Learning \& Education, v.5, n.4, p. 435-447, 2006.

BELLONI, M. L. Ensaio sobre a Educação a Distância no Brasil. Educ. Soc., Campinas, v.23, n. 78, p.117-142, 2002.

BLATTMANN, U. Modelo de gestão da informação digital on-line em bibliotecas acadêmicas na educação a distância: biblioteca virtual. Tese, Universidade Federal de Santa Catarina, Florianópolis, SC, Brasil, 2001.

COELHO, A. A.; SILVA, K. R. D.; TORRES, M. R. C.; FREITAS, L. B.; SERRA, M. R. S. A educação à distância como um desafio para os professores orientadores da especialização em educação do campo no município de São João dos Patos/MA. In: ESUD 2011 - VIII Congresso Brasileiro de Ensino Superior a Distância, Ouro Preto, p. 1-15 out. 2011.

CORRÊA, I. M. Planejamento estratégico e gestão pública por resultados no processo de reforma administrativa do estado de Minas Gerais. Revista de Administração 
Pública, v. 37, n. 3, p. 487-504, 2007. COSTA, D. M.; BARBOSA, F. V.; GOTO, M. M. M. O Novo Fenômeno da Expansão da Educação Superior no Brasil. REUNA, v. 16 , n. 1 , p. $1-15, .2011$

GARCEZ, E. M. S.; RADOS, G. J. V. Necessidades e expectativas dos usuários na educação a distância: estudo preliminar junto ao Programa de Pós-Graduação em Engenharia de Produção da Universidade Federal de Santa Catarina. Ci. Inf., Brasília, v. 31, n. 1, jan. p. 23, 2002.

GATTI, B. A.; BARRETO, E. S. S. Professores do Brasil: impasses e desafios. UNESCO. Brasília, 294 p. 2009.

\section{LIU, O. L. "Student Evaluation of}

Instruction: In the New Paradigm of Distance Education." Research in Higher Education, v.53, n. 4, p. 471-486, 2012.

MACHADO, R. PINTO, A. Reflexão sobre as consequências e a repercussão da educação a distância (EaD). Revista Eletrônica Gestão \& Saúde. Edição Especial. dez. 2012.

MALHEIROS, A. P. S.; FERRAZ, D. P. A.; MUENCHEN, C. Formadores em

formação: possibilidades e limites em um curso de licenciatura em física na modalidade a distância. In: ESUD 2011 - VIII Congresso Brasileiro de Ensino Superior a Distância, Ouro Preto, p. 1-17, out. 2011.

MARCONI, M. A.; LAKATOS, E. M. Metodologia do Trabalho Científico. 6. ed. São Paulo: Atlas, p. 1-22, 2001.

MATIAS-PEREIRA, J. Políticas públicas de educação no Brasil: a utilização da EAD como instrumento de inclusão social. Journal of Technology Management \& Innovation, v. 2, p. 44-55, 2008.

MEC/INEP - Instituto Nacional de Estudos e Pesquisas Educacionais Anísio Teixeira.

Censo da Educação Superior 2012 Apresentação por Aloizio Mercadante. Brasília, 17 de setembro de 2013
MINISTÉRIO DA EDUCAÇÃO - MEC. O Plano de Desenvolvimento da Educação: razões, princípios e programas - PDE. Brasília, p. 1-43, 2007.

MO, S.; ZHAO, L. A reflective note on evaluation methods in management distance learning courses. Academy of Educational Leadership Journal, v. 16, n.4. p. 19-26, 2012.

MORÉ, R. P. O.; VIEIRA, G. T.; ARAUJO, M. S.; CABRAL, T. L. O.; COSTA, A. M. Educação a Distância e formação docente: o sistema Universidade Aberta do Brasil como forma de ampliar o acesso à educação superior. Revista Gestão Universitária na América Latina, p. 89-109, 2011.

PINTO, J. M. R. Financiamento da educação no Brasil: um balanço do governo FHC (1995-2002). Educ. Soc., Campinas, vol. 23 , n. 80 , p. $108-135$, setembro/2002.

REDPATH, L. Confronting the Bias Against On-Line Learning in Management Education. Academy of Management Learning \& Education, v.11, n. 1, p. 125-140, 2012.

TUDORESCU, N.; ZAHARIA, C.; ZAHARIA, G.C.; ZAHARIA, I. Human Capital Accumulation and Long-Run Economic Growth. Economics, Management, and Financial Markets, v. 5, n.4, p. 250-255, 2010.

UAB/CAPES. Portal Universidade Aberta do Brasil. Disponível em: $<$ http://uab.capes.gov.br/index.php?option=co m_content \&view $=$ article\&id=7\&Itemid=19> acesso em 06 de Março e 2013.

SARAIVA, Luiz Alex Silva; DE SOUZA NUNES, Adriana. A efetividade de programas sociais de acesso à educação superior: o caso do ProUni. Revista de Administração Pública, v. 45, n. 4, p. 941964, 2011. 